\title{
Pelatihan Dan Pendampingan "Bocah Gimmick" PAUD/TA Cut Nyak Dien Kelurahan Bunulrejo Kecamatan Blimbing Kota Malang
}

\author{
Nurin Fitriana ${ }^{1}$ \\ Universitas Wisnuwardhana Malang, nurinfitriana86@gmail.com \\ Esy Suraeni Yuniwati ${ }^{2}$ \\ Universitas Wisnuwardhana Malang, esy_unidha@yahoo.com \\ Any Ikawati ${ }^{3}$ \\ Universitas Wisnuwardhana Malang, anyunidha@gmail.com
}

\begin{abstract}
Abstrak
Kemampuan membaca, komunikasi verbal, dan mengenal objek merupakan kegiatan belajar bagi anak sejak dini. Hal ini menjadikan pentingnya proses pembelajaran anak saat menginjak usia sekolah lanjut. PAUD/TA Cut Nyak Dien merupakan salah satu satuan Pendidikan usia dini, kegiatan pembelajarannya sudah baik namun guru masih kesulitan pada saat pembelajaran kemampuan tersebut dan masih lemahnya kemampuan membaca pada beberapa siswa, selain itu juga masih belum memanfaatkan IPTEK. Padahal anak-anak sudah mengenal gadget untuk bermain (game edukatif) menggunakan IPTEK.. Dengan demikian perlu dipikirkan bagaimana memberikan kegiatan belajar yang menarik, menyenangkan dan interaktif menggunakan teknologi IPTEK. Kegiatan yang dilakukan ini bertujuan untuk 1) meningkatkan pengetahuan guru tentang penggunaan media pembelajaran dengan bantuan Iptek; 2) memberikan alat peraga pendukung proses belajar memanfaatkan teknologi elektronik berjudul BOCAH GIMMICK (Boleh Membaca Hebat pakai Game Interactive). Bertujuan untuk mempermudah proses pembelajaran yang memanfaatkan IPTEK sebagai sarana belajar. Target luaran berupa aplikasi alat belajar yang menarik dan interaktif dan alat pendukung cerdas cermat yang memanfaatkan teknologi elektronik.
\end{abstract}

Kata kunci : usia dini, teknologi, alat peraga

\begin{abstract}
The ability to read, verbal communication, and recognize objects is a learning activity for children from an early age. This makes the importance of the child's learning process at the age of high school. PAUD / TA Cut Nyak Dien is one of the early childhood education units, the learning activities are good but the teacher is still having difficulties when learning these abilities and the ability to read is still weak in some students, besides that, he also does not utilize science and technology. Even though children are familiar with gadgets to play (educational games) using science and technology. It is necessary to think about how to provide learning activities that are interesting, fun and interactive using science and technology technology. This activity aims to 1) increase teacher knowledge about the use of learning media with the help of science and technology; 2) provide props supporting the learning process using electronic technology titled BOCAH GIMMICK (Can Read Greatly using Game Interactive). Aim to facilitate the learning process that utilizes science and technology as a learning tool.
\end{abstract}


Jurnal Pengabdian Kepada Masyarakat

Output targets are interesting and interactive learning tools and quiz support tools that use electronic technology.

Keywords: early age, technology, teaching props

\section{Pendahuluan}

TA Cut Nyak Dien, merupakan salah satu sekolah pra Sekolah Dasar yang termasuk di kunjungi oleh Tim PKM. Sekolah ini memiliki keunikan siswa yaitu banyak yang berasal dari luar kota malang bahkan luar jawa, sehingga kemampuan berbahasa juga beragam. Selain itu hasil diskusi bersama mitra, Tim PKM menemukan adanya permasalahan terkait kendala yang dialami guru saat mengajarkan anak untuk membaca cepat yang menyenangkan, menarik dan tidak membosankan. Kemampuan memberi nama objek juga menjadi kendala anak-anak belajar saat pembelajaran yang dilakukan dengan cara konvemsional. Baik cara penamaan dalam Bahasa indonesia ataupun Bahasa daerah. Saat berdiskusi dengan Ibu Kepala sekolah Ibu. Budi Hastinaningsih, S.Pd, beliau menyampaikan bahwa 'keterampilan dan kemampuan mengajar saja tidak cukup butuh adanya stimulus untuk siswa dalam kegiatan pembelajaran sehingga lebih menarik dan interaktif'.

Di wilayah kota Malang, banyak terdapat sekolah PAUD/TA yang memberikan pelayanan pembelajaran pada anak usia dini, tetapi masih sedikit yang memberikan sarana fasilitas pembelajaran yang berbasis teknologi, bahkan menurut pengamatan yang dilakukan Tim PKM dari lima lembaga PAUD/TA tidak ada yang memiliki alat atau media pembelajaran yang menggunakan basis teknologi yang menarik dan menyenangkan untuk kegiatan belajar khususnya untuk menggali kemampuan membaca cepat pada anak.

Sumber daya manusia yang ada di TA Cut Nyak Dien masih tergolong rendah meskipun sekolah ini terletak di tengan kota tetapi sebagian besar guru pengajar hanya lulusan SMA. Hal ini menjadikan proses belajar di TA Cut Nyak Dien masih dilakukan dengan cara konvensional.

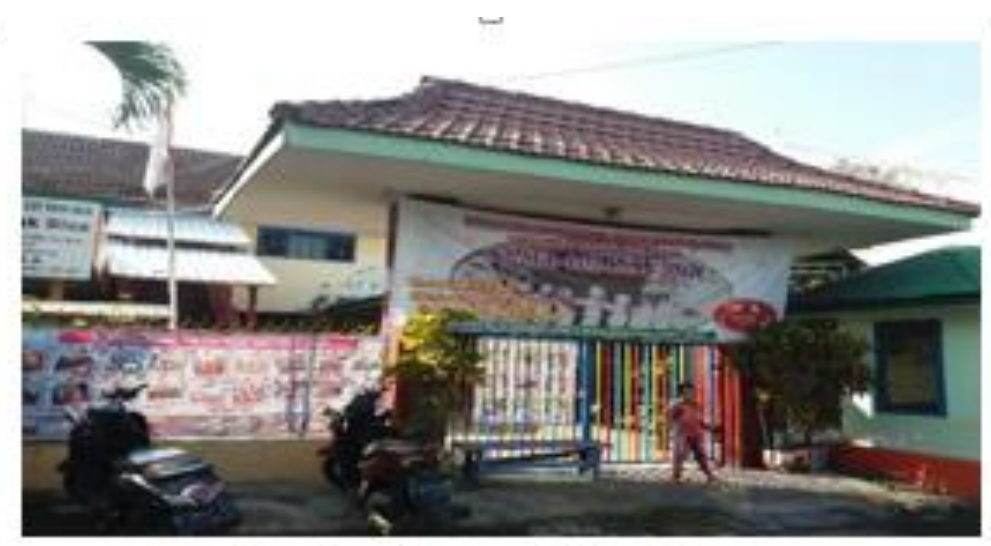

Gambar 1. Foto Sekolah 


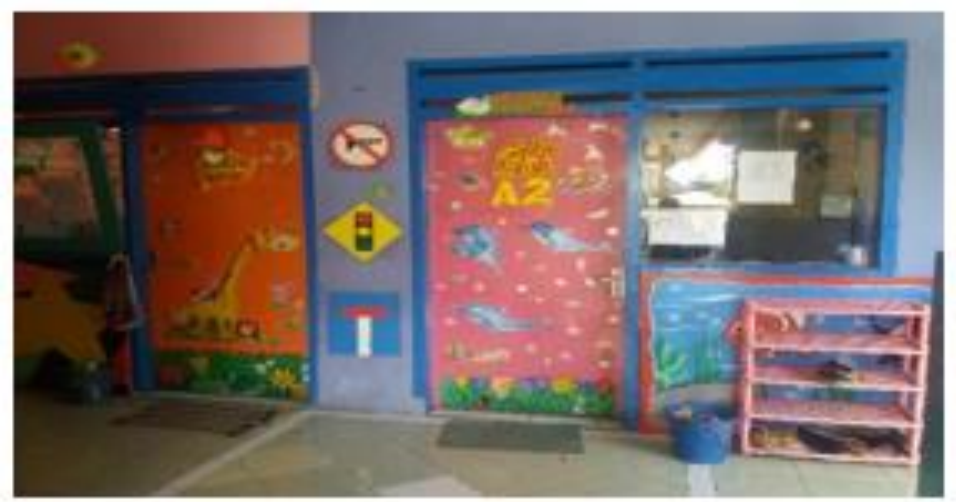

Gambar 2. Foto Keadaan Kelas

Berdasarkan diskusi Tim PKM bersama mitra yang diwakili oleh Ibu Kepala sekolah Ibu. Budi Hastinaningsih, S.Pd menyampaikan pada Tim mengharapkan dapat memberikan fasilitas pembelajaran untuk kemampuan membaca, berbahasa dan mengenal objek yang dapat terasa menyenangkan bagi anak untuk belajar sehingga anak tidak cepat merasa bosan di kelas saat proses kegiatan belajar berlangsung. Oleh karena itu seiiring kemajuan teknologi pembelajaran maka sangat perlu dicari bagaimana caranya agar sekolah tidak dirasa monoton dan membosankan. Sekolah harus dirasakan siswa sebagai tempat yang menarik, menggugah motivasi belajar, menjawab keingintahuan siswa dan menyenangkan.

Diantara banyak tujuan pendidikan dalam PAUD, terdapat aspek kemampuan Bahasa yang wajib dimiliki oleh anak usia dini.

Berdasarkan buku pedoman kurikulum 2013 terdapat kompetensi bidang Bahasa yaitu: 1) memahami Bahasa reseptif (menyimak dan membaca); 2) memahami Bahasa ekspresif (mengungkapkan Bahasa secara verbal dan nonverbal); 3) Mengenal keaksaraan awal melalui bermain; 4) mengenal gambar di lingkungan dan makhluk hidup; 5) mampu membaca dengan baik dan benar. Berdasarkan kompetensi dasar dan indikator pembelajaran yang harus dicapai di bidang Bahasa tersebut maka mitra menyampaikan perlu suatu alat permainan edukatif yang menyenangkan untuk anakanak belajar.

Seluruh aspek perkembangan anak dikembangkan melalui program PAUD ini dalam aktivitas belajar yang menyenangkan karena dilaksanakan dalam kegiatan bermain. Aspek perkembangan sebagai potensi bawaan anak tidak akan berkembang tanpa stimulasi dari orang tua di rumah dan pendidik anak di sekolah. PAUD merupakan peletak dasar berbagai perkembangan anak yang akan sangat berpengaruh pada proses kehidupan anak di masa mendatang (Maryatun, 2016).

Oleh karena itu Tim PKM bersama mitra berdiskusi untuk penggunaan media bantu belajar atau alat permainan edukatif yang menyenangkan sehiggadalam proses pembelajarannya diharapkan dapat meningkatkan proses belajar anak-anak yang lebih menarik. Pada akhirnya diharapkan dapat meningkatkan hasil belajar yang dicapai. Hal ini didukung oleh banyak jurnal ilmiah yang membahas tentang penggunaan media dalam pembelajaran, menyebutkan bahwa proses dan hasil belajar pada siswa menunjukkan perbedaan yang signifikan antara pembelajaran tanpa media dengan pembelajaran menggunakan media. Oleh karena itu penggunaan 
Jurnal Pengabdian Kepada Masyarakat

media pembelajaran sangat dianjurkan untuk mempertinggi kualitas pembelajaran. Banyak jurnal yang mengemukakan hal ini, salah satunya yaitu:

"Furthermore, games have become a new form of interactive content and game playing provides an interactive, collaborative platform for learning purposes: Digital games that allow collaborative learning producenew ideas as well as exchanging information, simplifying problems, and resolving tasks."(Noemí \& Máximo, 2014)

Selain dikarenakan minimnya penyediaan alat permainan di sekolah yang menyenangkan bagi siswa dengan menggunakan basis teknologi, Tim PKM merasa perlu diadakan pelatihan bagi guru guna peningkatan kemampuan penggunaan Iptek bagi guru untuk kegiatan pembelajaran serta perlu adanya penyediaan media pembelajaran yang menunjang proses belajar, salah satunya yang dapat menggali pemahaman siswa untuk kemampuan berbahasa, membaca dan mengenal gambar. Siswa dapat mengkonstruksi pengetahuannya sendiri dengan alat pembelajaran tersebut. Hal ini berdasarakan hasil diskusi bersama Ibu Budi Hastinaningsih, S.Pd, beliau mengemukakan bahwa perlu adanya alat pembelajaran edukatif yang dapat mempermudah guru dalam mengajarkan kemampuan ank untuk membaca cepat yang menyenangkan. Selain itu juga adanya pelatihan bagi guru dikarenakan melihat latar belakang pendidikan para guru pendidik di TA Cut Nyak Dien yang kurang memadai.

Alat Peraga Edukatif (APE) dirancang untuk memberikan informasi atau menanamkan sikap tertentu, termasuk memberikan pengalaman belajar baik kognitif, afektif, motorik, bahasa maupun sosial, termasuk didalamnya permainan tradisional maupun modern (Sulastri, Rahma, \& Hakim, 2017).

\section{Metode}

Metode pendekatan yang akan digunakan untuk membantu mitra adalah dengan memberikan pelatihan kepada guru-guru entang penggunaan IPTEK dalam pembelajaran dan memberikan alat pendukung edukatif berbantuan teknologi elektronik yang menyenangkan dan menarik bagi siswa. Hal ini dikarenakan anak usia dini saat belajar biasanya sangat cepat merasa bosan, menyerah dan merasa tidak menarik jika diajarkan dengan cara atau teknik pengajaran yang konvensional. selain itu saat pelatihan, melihat peningkatannya dapan dianalisis dengan cara Teknik analisis deskriptif melalui angket

\section{Hasil Dan Pembahasan}

\section{A. Program Perencanaan Pelatihan dan Rancangan media}

Kegiatan pelatihan bagi guru bertujuan untuk memberikan peningkatan pengetahuan tentang pentingnya penggunaan IPTEK dalam pembelajaran. Agar sisiwa merasa tertarik, senang, dan interaktif dalam belajar, sehingga perlu dipikirkan penggunaan media pembelajaran. Dan alat pendukung yang menarik. Alur pengabdian kepada masyarakat yang dilakukan: 
Jurnal Pengabdian Kepada Masyarakat

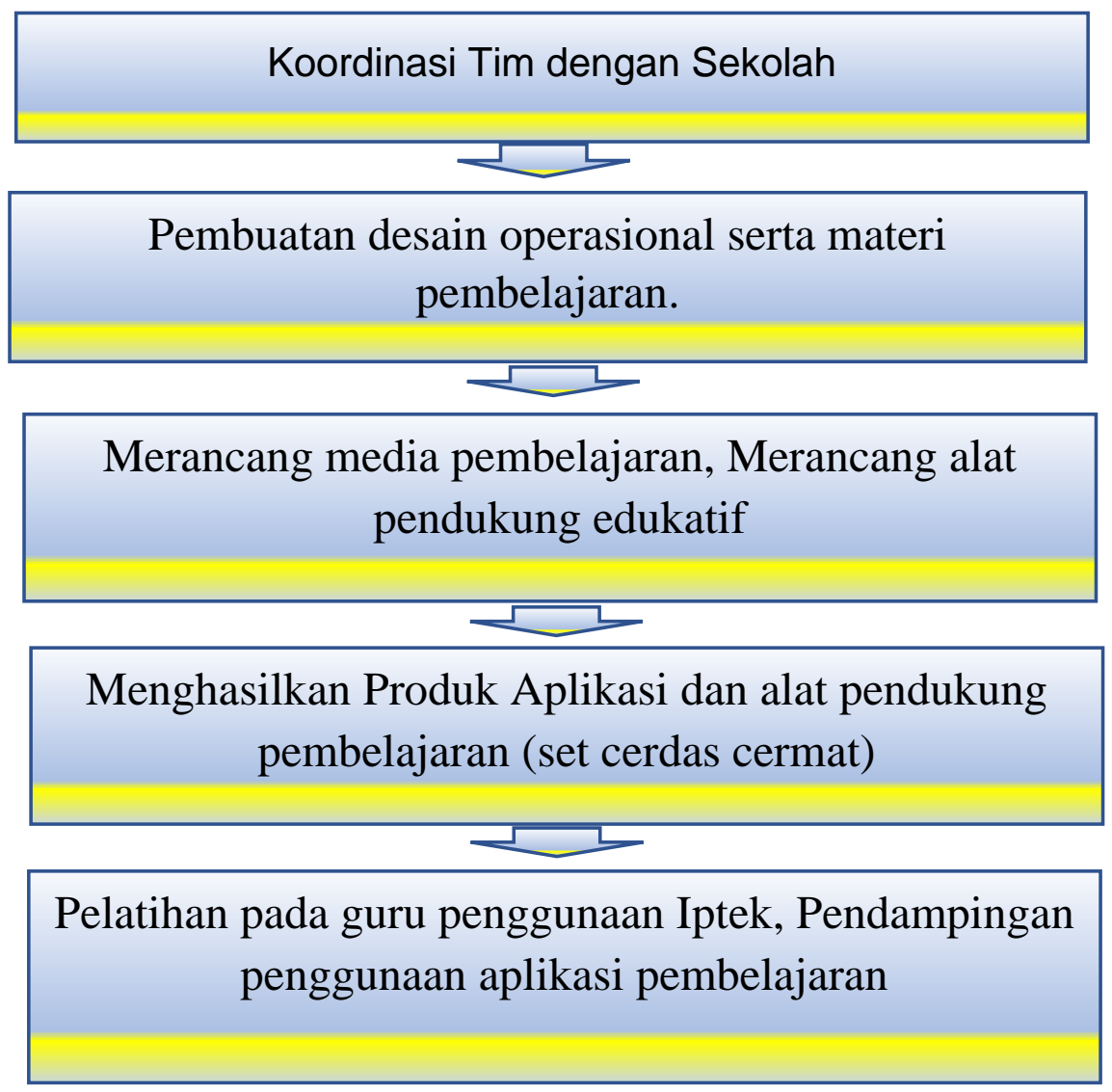

Gambar 3. Digram alur pengabdian

B. Kegiatan Pelatihan

Pelatihan bertujuan untuk memberikan pengetahuan tentang penggunaan IPTEK pada guru-guru Taman Kanak-kanak. Kegiatan ini mendatangkan narasumber Bp. Deni Trias Utomo, S.Si, M.T. Beliau adalah dosen Teknologi Informasi Politeknik Negeri Jember dan Universitas Wisnuwardhana Malang, selain itu juga praktisi Pendidikan tentang penggunaan teknologi dalam pembelajaran. Tema kegiatan pelatihan adalah "Pelatihan Penggunaan IPTEK Dalm Pembelajaran Taman KanakKanak”. Dilaksanakan tanggal 13 Mei 2019 bertempan di TK Cut Nyak Dien Malang.

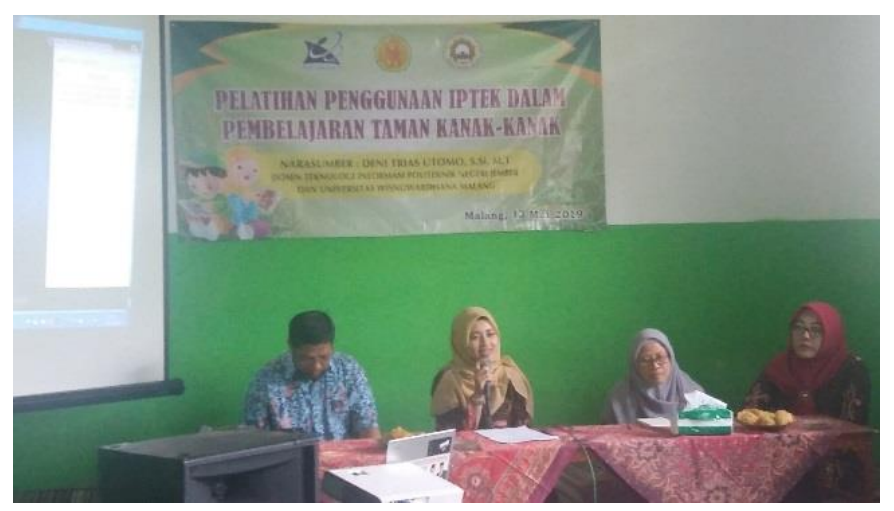

Gambar 4. Foto Narasumber dan Tim PKM 
Jurnal Pengabdian Kepada Masyarakat

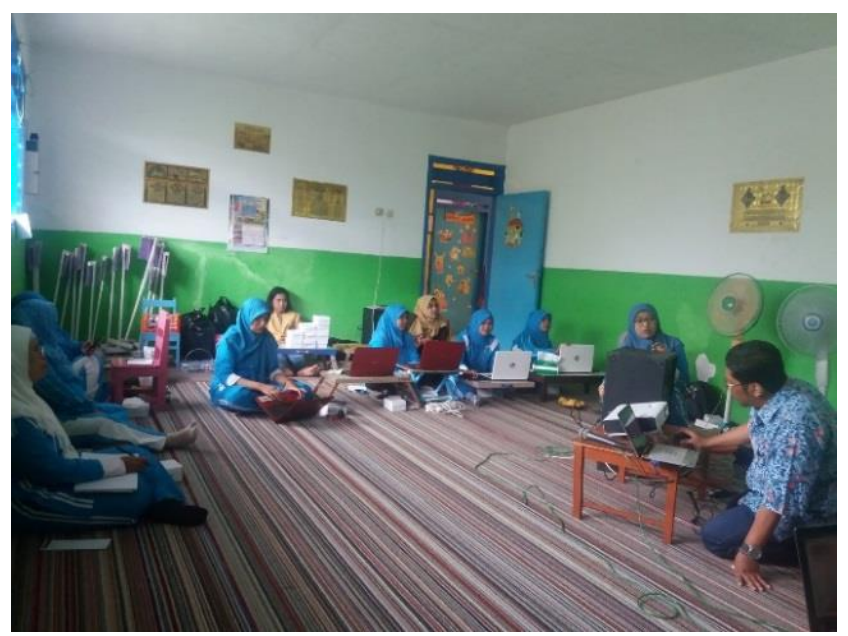

Gambar 5. Kegiatan pelatihan

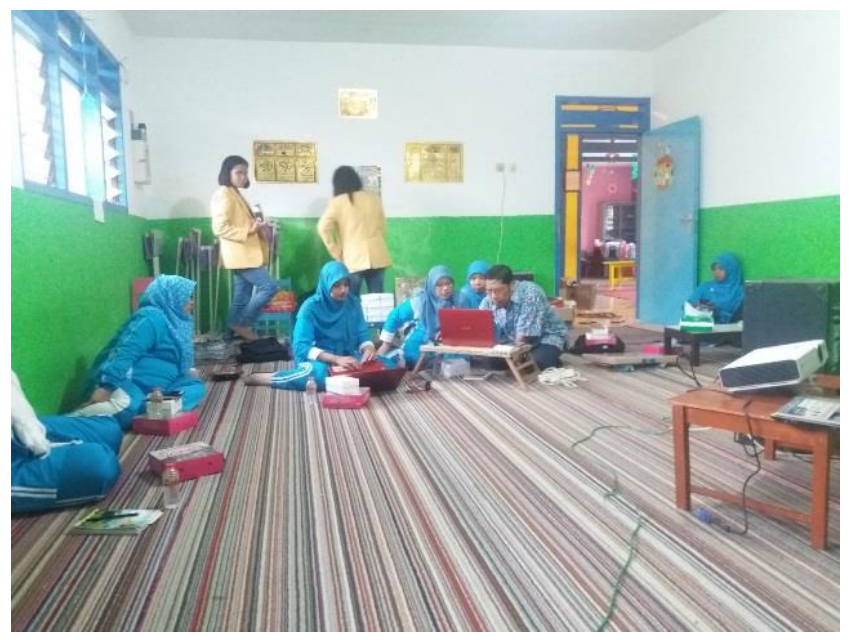

Gambar 6. Narasumber langsung melatih guru

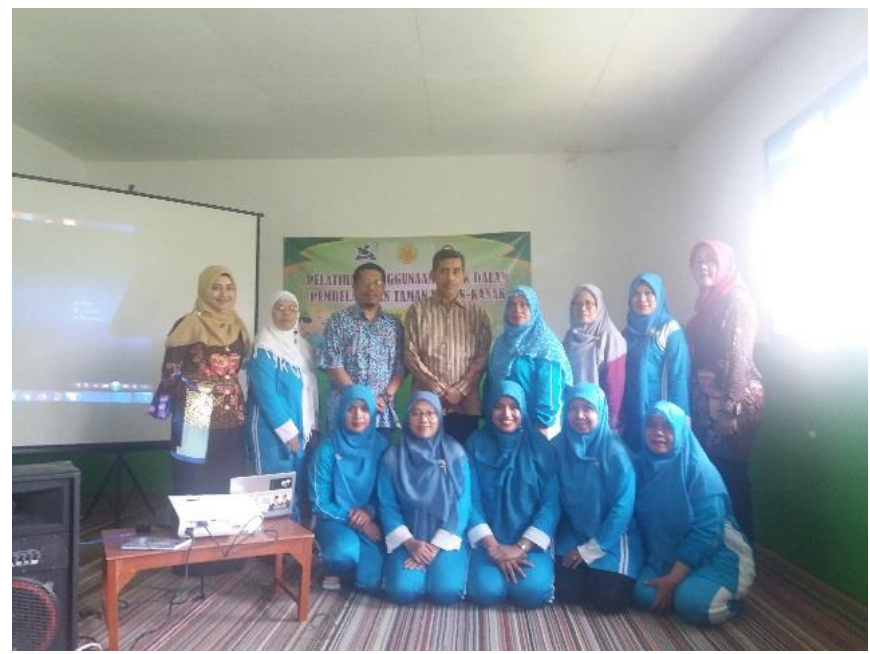

Gambar 7. Foto Bersama para guru 
C. Pendampingan pada siswa dengan alat pendukung cerdas cermat

Dilaksanakan tanggal 17 Mei 2019 bertempan di TK Cut Nyak Dien Malang. Media pembelajaran yang dibuat adalah software aplikasi flash diberikan layanan belajar berupa Gambar dan Materi singkat mengenai keterangan keterangan yang berkaitan dengan gambar. Sehingga anak dapat belajar membaca rangkaian kalimat, menggali kemampuan kognitifnya dan guru juga bisa memberikan cerita-cerita tambahan mengenai objek yang dipelajari.

Bermacam cara yang dapat dikembangkan untuk proses pembelajaran. Disajikan dalam buku panduan ini ada 2 (dua) strategi pembelajaran yaitu, Rancangan Konsep Cerdas Cermat dan Rancangan Belajar Mandiri. Dengan demikian pengukuran kemampuan membaca anak:

1. Rancangan Konsep Cerdas Cermat.

Guru dapat menilai kecepatan siswa menjawab soal yang diberikan di media atau soal pengembangan dari guru secara verbal.

2. Rancangan Belajar Mandiri.

Guru dapat menilai kemapuan akhir siswa melalui score yang diperoleh saat latihan.

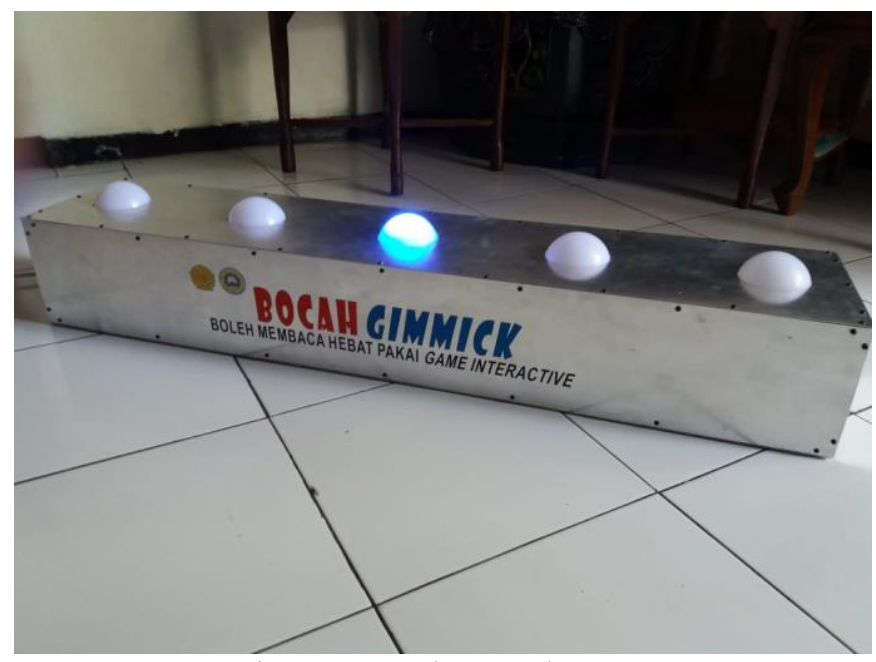

Gambar 7. Set Alat Cerdas Cermat

B. Rancangan Belajar BOCAH GIMMICK

SKEMA 1

RANCANGAN DENGAN KONSEP CERDAS CERMAT

Berikut adalah bagan alir kegiatan di kelas yang dilaksanakan untuk strategi belajar dengan alat pendampng berupa bel cerdas cermat. 
Jurnal Pengabdian Kepada Masyarakat

\begin{tabular}{|l|}
\hline Guru menyiapkan LDC, Laptop dan Set alat Cerdas Cermat \\
\hline $\begin{array}{c}\text { Guru membuka aplikasi pembelajaran Flash di laptop dan } \\
\text { menampilkannya di layar LCD }\end{array}$ \\
\hline $\begin{array}{c}\text { Guru memulai kegiatan menggali kognitif siswa, dengan Materi } \\
\text { dan Latihan dalam Aplikasi. }\end{array}$ \\
\hline Siswa Menjawab dengan menekan tombol pada alat set cerdas \\
cermat. \\
\hline
\end{tabular}

\section{Gambar 8. Skema cerdas cermat}

Adapun beberapa kegiatan yang dilakukan:

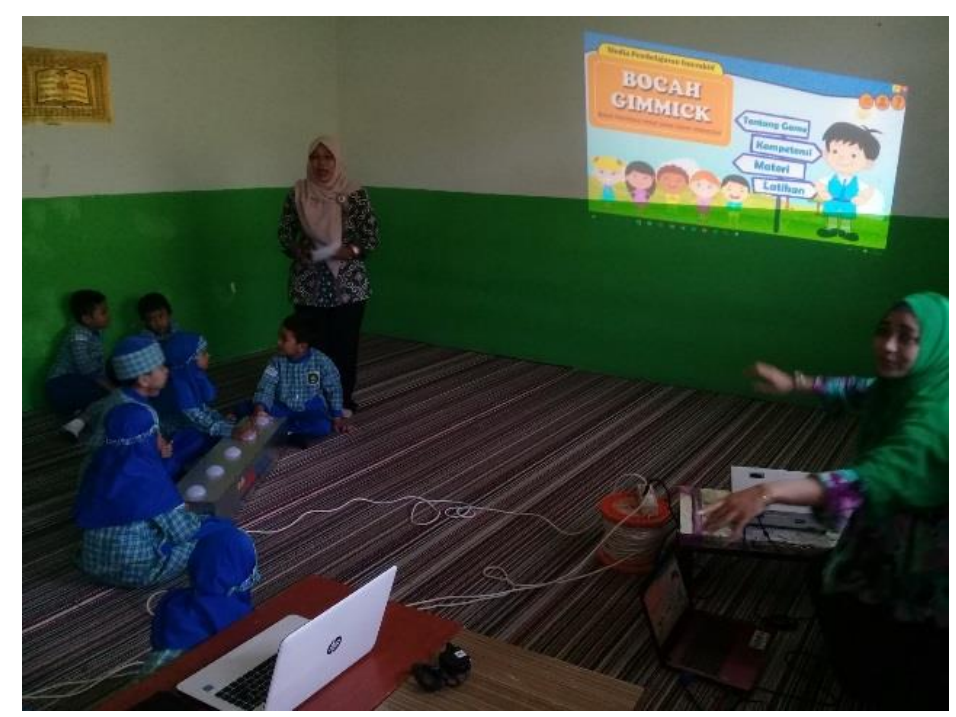

Gambar 9. Pembelajran dengan metode cerdas cermat 
Jurnal Pengabdian Kepada Masyarakat

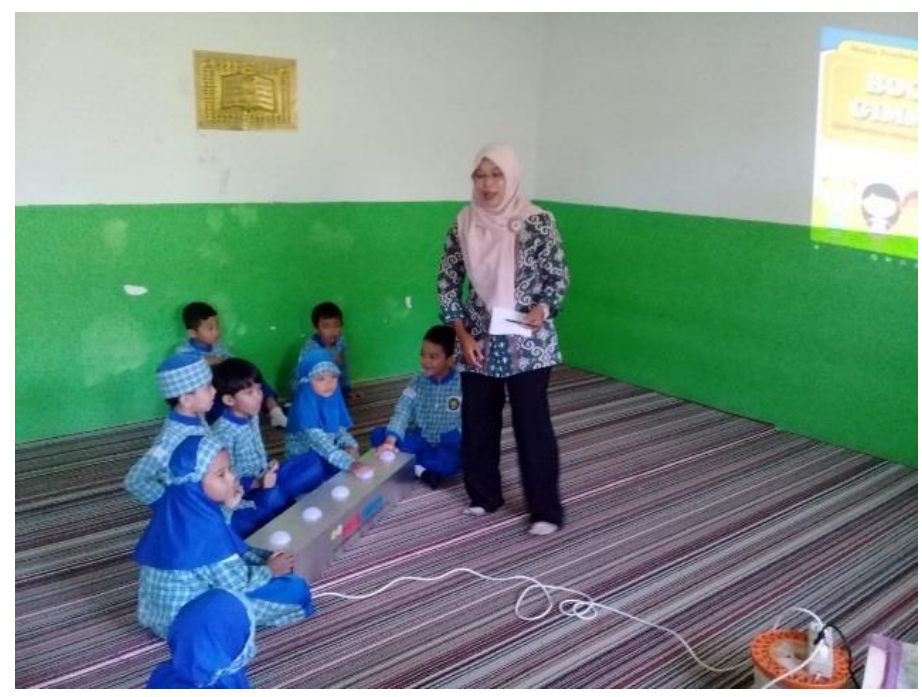

Gambar 10. Interaksi Guru dengan siswa dalam menjelaskan materi

\section{SKEMA 2}

\section{RANCANGAN BELAJAR MANDIRI}

Berikut adalah bagan alir kegiatan di kelas yang dilaksanakan untuk strategi belajar anak-anak beajar materi ajar dengan cara mandiri, yaitu langsung membuka aplikasi di laptop dengan pendampingan dari ibu guru.

Adapun Kegiatan-kegiatan yang dilakukan:

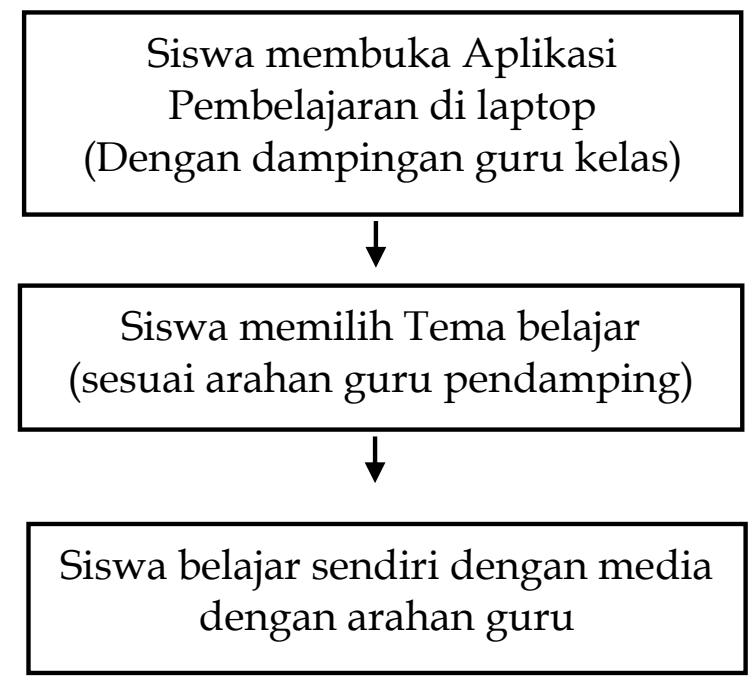

Gambar 11. Skema Belajar Mandiri 
Jurnal Pengabdian Kepada Masyarakat

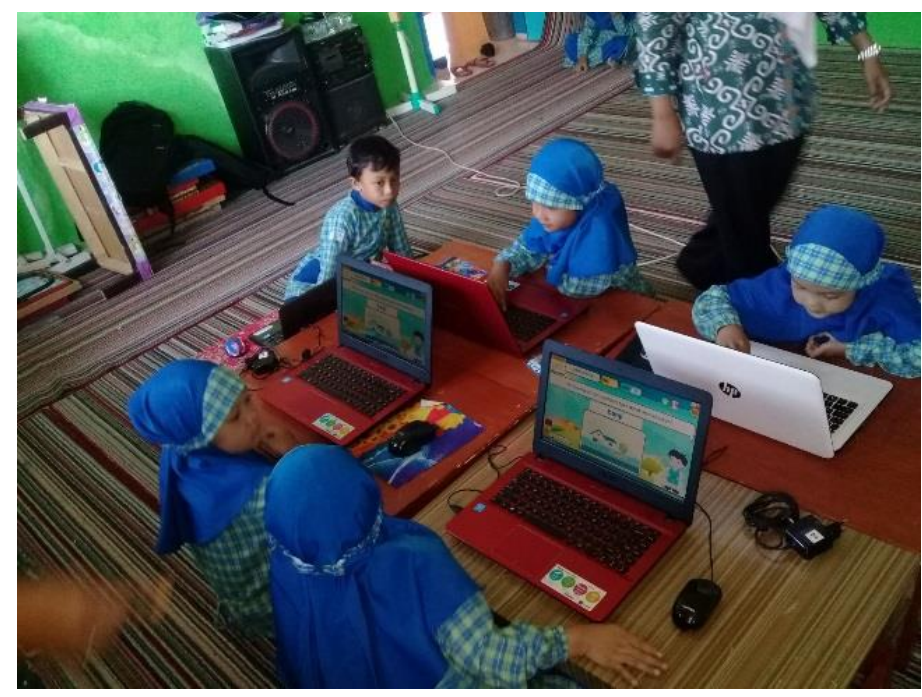

Gambar 12 . Siswa menggunakan laptop belajar secara mandiri dengan instruksi Guru

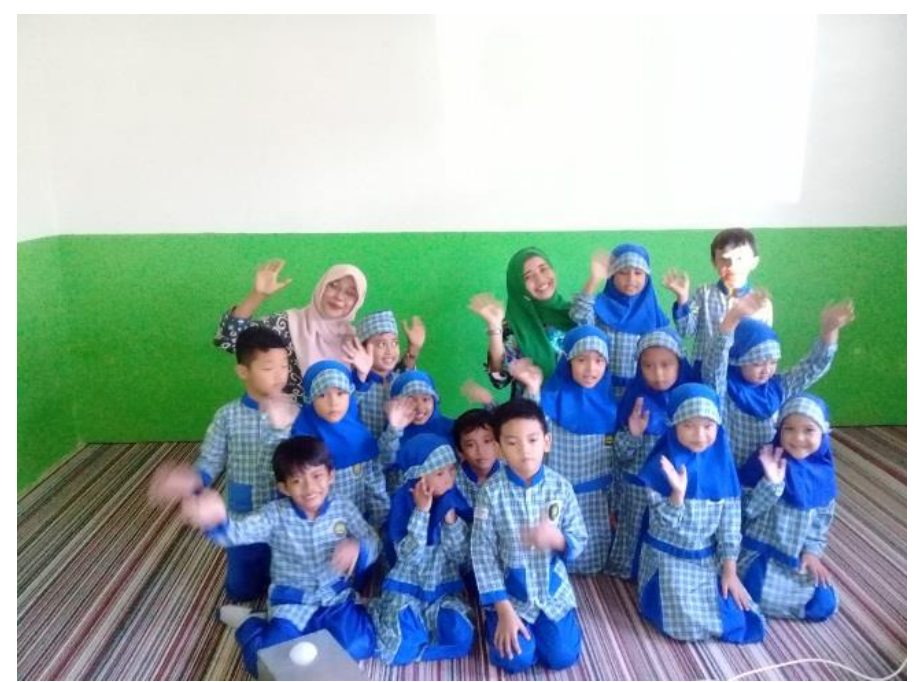

Gambar 13. Foto Bersama siswa-siswi

\section{Simpulan Dan Rekomendasi}

TA Cut Nyak Dien merupakan Satuan pendidikan yang mendidik anak usia dini dan taman kanak-kanak. Di era IPTEK ini sangat diperlukan ide-ide kreatif dari guru untuk mencarikan solusi kemudahan belajar yang menarik, menyenangkan bagi anak dan interaktif. Hal ini sangat bermanfaat bagi kemajuan pendidikan pada umumnya dan pemahaman pada anak dengan cara konstruksi pengetahuan yang lebih mandiri. Konsep-konsep ide dari guru yang ditemukan nantinya dapat diterapkan dikelas.

Kegiatan pelatihan dan pendampingan serta alat pendukung berupa cerdas cermat yang diberikan oleh Tim menjadi salah satu contoh kegiatan yang berbasis IPTEK dalam kegiatan pembelajaran yang di rasa menarik dan menyenangkan bagi siswa. Berdasarkan hasil diskusi lanjut tentang hasil kegiatan dengan kepala sekolah, menunjukkan respon positif tentang terselenggaranya kegiatan pengabdian kepada masyarakat. 
Jurnal Pengabdian Kepada Masyarakat

Berdasarkan kegiatan yang dilakukan adapun saran yang dapat dilakukan selanjutnya adalah menfasilitasi ide dan mengembangkan media pembelajaran berbasis IPTEK yang dimungkinkan untuk mata pelajaran yang lain.

\section{Daftar Pustaka}

Buku Profil Sekolah TA Cut Nyak Dien periode 2016/2017 - 2019/2020. Malang: TA Cut Nyak Dien

Kurikulum PAUD/RA Berbasis Kurikulum 2013. Malang : InPress.

Maryatun, I. B. (2016). Peran Pendidik PAUD dalam Membangun Karakter Anak. Jurnal Pendidikan Anak.

Noemí, P.-M., \& Máximo, S. H. (2014). Educational games for learning. Universal Journal of Educational Research. https:// doi.org/10.13189/ujer.2014.020305

Sulastri, Y. L., Rahma, A., \& Hakim, L. L. (2017). IbM Pembuatan Alat Permainan Edukatif (APE) Ramah Anak Bagi Guru Paud di Kota Bandung. JURNAL PENGABDIAN KEPADA MASYARAKAT. https://doi.org/10.30999/jpkm.v7i2.177 